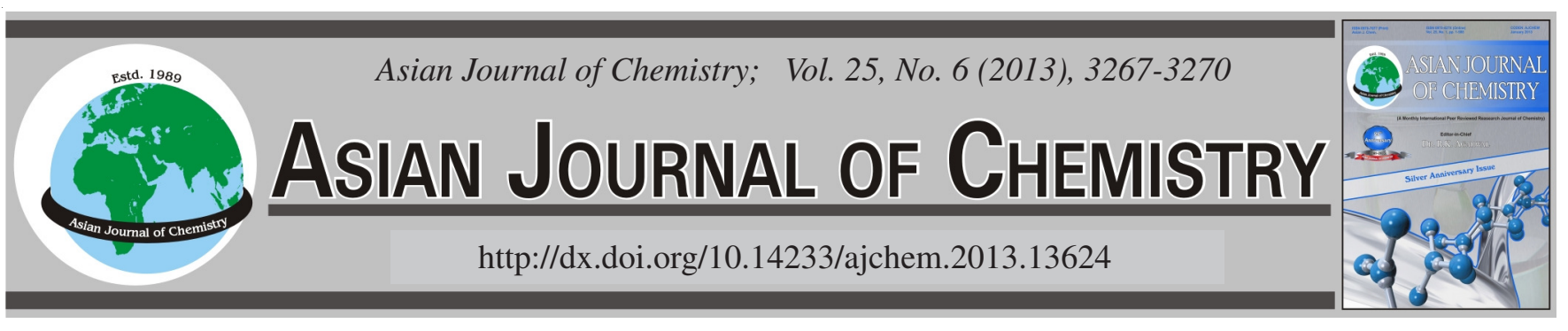

\title{
Synthesis and Thermal Decomposition Kinetics of Gd(III) Complex with Unsymmetrical Schiff Base Ligand
}

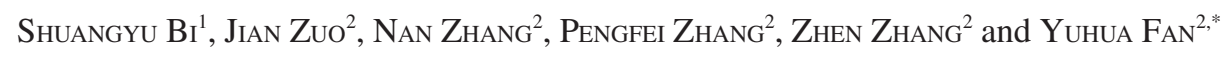

${ }^{1}$ Center for Theoretical Biology, Academy for Advanced Interdisciplinary Studies, Peking University, Haidian District, Beijing 100871, P.R. China ${ }^{2}$ Key Laboratory of Marine Chemistry Theory and Technology, Ministry of Education, College of Chemistry and Chemical Engineering, Ocean University of China, Qingdao 266100, P.R. China

*Corresponding author: E-mail: fanyuhua301@163.com

(Received: 18 February 2012;

Accepted: 17 December 2012)

AJC-12563

\begin{abstract}
A new unsymmetrical solid Schiff base (LLi) was synthesized using L-lysine, $o$-vanillin and 2-hydroxy-1-naphthaldehyde. Solid gadolinium(III) complex of this ligand $\left[\mathrm{GdL}\left(\mathrm{NO}_{3}\right)\right] \mathrm{NO}_{3} \cdot 2 \mathrm{H}_{2} \mathrm{O}$ has been prepared and characterized by elemental analyses, IR spectra, ${ }^{1} \mathrm{H}$ NMR spectra, UV spectra and molar conductance. The thermal decomposition kinetics of the complex for the second stage was studied under non-isothermal condition by TG and DTG methods. The kinetic equation may be expressed as: $\mathrm{d} \alpha / \mathrm{dt}=\mathrm{Ae}^{-\mathrm{E} / \mathrm{RT}}(1-\alpha)^{2}$. The kinetic parameters (E, A), activation entropy $\Delta \mathrm{S}^{\neq}$and activation free-energy $\Delta \mathrm{G}^{\neq}$were also gained.
\end{abstract}

Key Words: Unsymmetrical Schiff base, Gd(III) complex, Thermal decomposition.

\section{INTRODUCTION}

Some Schiff base complexes derived from amino acids are particularly active in biology. Recently, studies of such metal complexes of mono-Schiff bases have been reported ${ }^{1-4}$. In this study, a new unsymmetrical Schiff base ligand has been synthesized starting from L-lysine, $o$-vanillin and 2-hydroxy1-naphthaldehyde by a new method. Since this ligand dose not exist in literature, this paper deals with the preparation and characterization of the complex formed from this Schiff base ligand with $\mathrm{Gd}(\mathrm{III})$. As thermal aspects are essential in the complex, the thermal decomposition process of $\left[\mathrm{GdL}\left(\mathrm{NO}_{3}\right)\right] \mathrm{NO}_{3}$. $2 \mathrm{H}_{2} \mathrm{O}$ by TG-DTG is described in this paper and the corresponding non-isothermal kinetics are discussed.

\section{EXPERIMENTAL}

All the reagents used in this work were of analytical grade. Hydrated gadolinium(III) nitrate was prepared by the reaction of gadolinium(III) oxide with nitric acid.

Mono-Schiff base (HR): L-lysine (2.193 g, $15 \mathrm{mmol}$ ) was dissolved in $230 \mathrm{~mL}$ of anhydrous ethanol and methanol in the proportion of $1: 1(\mathrm{v} / \mathrm{v})$ and heated for $1.5 \mathrm{~h}$ at $55-50{ }^{\circ} \mathrm{C}$, filtered. $o$-Vanillin $(2.282 \mathrm{~g}, 15 \mathrm{mmol})$ dissolved in $40 \mathrm{~mL}$ of hot ethanol was added drop-wise to the above filtered solution and stirred for $2 \mathrm{~h}$ at $50-55^{\circ} \mathrm{C}$ to give a light yellow precipitate. The precipitate was collected by filtration, washed with ethanol and dried in vacuum. Yield $2.943 \mathrm{~g}(70 \%)$; m.p. 232-234 ${ }^{\circ} \mathrm{C}$.
Unsymmetrical Schiff base (LLi): Mono-Schiff base (HR) (1.402 g, $5.0 \mathrm{mmol})$ and lithium hydroxide $(0.120 \mathrm{~g}, 5.0$ $\mathrm{mmol}$ ) were dissolved in $60 \mathrm{~mL}$ anhydrous methanol and isopropanol in the proportion of 1:5 (v/v) and stirred for $1 \mathrm{~h}$ at 50-55 ${ }^{\circ} \mathrm{C} .2$ 2-Hydroxy-l-naphthaldehyde (0.861 g, $\left.5.0 \mathrm{mmol}\right)$ dissolved in $10 \mathrm{~mL}$ isopropanol was added drop-wise to the above solution and stirred for $4 \mathrm{~h}$ at $50-55^{\circ} \mathrm{C}$ to give a yellow precipitate. The precipitate was collected by filtration, washed with ethanol and dried in vacuum. The yield of the Schiff base (LLi) was $1.563 \mathrm{~g} \mathrm{(71 \% )} \mathrm{and} \mathrm{the} \mathrm{purity} \mathrm{was} \mathrm{higher} \mathrm{than} 99 \%$. Calcd. (\%) for $\mathrm{C}_{25} \mathrm{H}_{25} \mathrm{~N}_{2} \mathrm{O}_{5} \mathrm{Li}$ (440.4): C, 68.18; H, 5.72; N, 6.36, found (\%): C, 67.24; H, 5.77; N, 6.34.

Preparation of the complex: The unsymmetrical Schiff base (1.321 g, $3.0 \mathrm{mmol})$ dissolved in $65 \mathrm{~mL}$ anhydrous methanol and isopropanol in the proportion of 1:5 (v/v) was mixed with $\mathrm{Gd}\left(\mathrm{NO}_{3}\right)_{3} \cdot 6 \mathrm{H}_{2} \mathrm{O}(1.355 \mathrm{~g}, 3.0 \mathrm{mmol})$ dissolved in $15 \mathrm{~mL}$ anhydrous ethanol and stirred for $3 \mathrm{~h}$ at $50-55^{\circ} \mathrm{C}$ to give yellow precipitate. The precipitate was filtered, recrystallized with anhydrous methanol and isopropanol in the proportion of 1:5 (v/v) and dried in vacuum. The yield of the complex was 1.532 $\mathrm{g}(68 \%)$ and the purity was higher than $99 \%$. Calcd. (\%) for $\mathrm{C}_{25} \mathrm{H}_{29} \mathrm{~N}_{4} \mathrm{O}_{13} \mathrm{Gd}$ (750.8): C, 39.99; H, 3.89; N, 7.46; Gd, 20.95, found (\%): C, 40.09; H, 3.76; N, 7.52; Gd, 21.96 .

Elemental analyses were carried out with a model 2400 Perkin-Elmer analyzer. The metal content was determined gravimetrically. Infrared spectra of the ligand and complex were recorded in $\mathrm{KBr}$ pellets using a Bio-Rad FTS 165 
spctrophotometer. The ultraviolet spectra were recorded on a Shimadzu UV-3000 spctrophotometer in DMSO. The molar conductance was measured with a Shanghai DDSJ-308A conductivity meter. ${ }^{1} \mathrm{H}$ NMR spectra were recorded in DMSO$d_{6}$ as the solvent at $600 \mathrm{MHz}$ with a JNM ECP-600 spectrometer using tetramethylsilane (TMS) as an internal reference. Thermogravimetric measurements were made using a PerkinElmer TGA7 instrument. The heating rate was programmed to be $10{ }^{\circ} \mathrm{C} / \mathrm{min}$ with a protecting stream of $\mathrm{N}_{2}$ flowing at a rate of $40 \mathrm{~mL} / \mathrm{min}$. The mass spectrogram of the ligand was recorded on a Finnegan MAT-212 mass spectrometer.

\section{RESULTS AND DISCUSSION}

The reaction activity and steric hindrance of the two $-\mathrm{NH}_{2}$ in L-lysine is different and the $-\mathrm{NH}_{2}$ in a seat have higher activity than the $-\mathrm{NH}_{2}$ in e seat because of the induced effect of $-\mathrm{COO}^{-}$in L-lysine. When the molar ratio of L-lysine and $o$-vanillin was $1: 1$, the $o$-vanillin reacted with the $-\mathrm{NH}_{2}$ in a seat first forming the mono-Schiff base. Then the mono-Schiff base reacted with 2-hydroxy-1-naphthaldehyde forming the unsymmetrical di-Schiff base. The synthesis reactions of the ligand are shown in Fig. 1. The synthesis of the complex may be represented as:
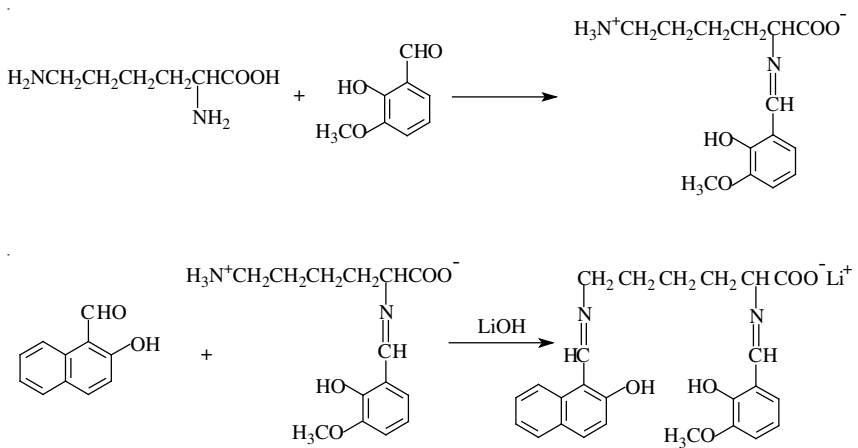

Fig. 1. Preparation of the ligand

$$
\begin{array}{r}
\mathrm{Gd}\left(\mathrm{NO}_{3}\right)_{3} \cdot \mathrm{xH}_{2} \mathrm{O}+\mathrm{LLi}=\left[\mathrm{GdL}\left(\mathrm{NO}_{3}\right)\right] \mathrm{NO}_{3} \cdot 2 \mathrm{H}_{2} \mathrm{O} \\
+\mathrm{LiNO}_{3}+(\mathrm{x}-2) \mathrm{H}_{2} \mathrm{O}
\end{array}
$$

The molar conductance value of the complex determined in DMSO is $50.8 \mathrm{~S} \mathrm{~cm}^{2} \mathrm{~mol}^{-1}$, which is expected for $1: 1 \mathrm{elec}-$ trolyte $^{5}$. This suggests that one nitrate ion is within the coordination sphere and the second is ionic and not coordinated. The complex is stable in air and soluble in DMSO and DMF; however insoluble in benzene, acetone or diethyl ether.

Mass spectrum: The mass spectrum of LLi is shown in Fig. 2. The molecular weight of LLi is 440, which indicates that the reaction product of L-lysine with $o$-vanillin and 2hydroxy-1-naphthaldehyde is an unsymmetrical di-Schiff base.

IR Spectra: The shift of $v(\mathrm{C}=\mathrm{N})$ from $1633 \mathrm{~cm}^{-1}$ in the ligand to $1644 \mathrm{~cm}^{-1}$ in the complex, suggests the formation of a $\mathrm{C}=\mathrm{N}-\mathrm{La}$ bond system. The vibration $\mathrm{v}(\mathrm{Ar}-\mathrm{O})$ of LLi occurs at $1228 \mathrm{~cm}^{-1}$ and the shift to lower frequency $c a .13 \mathrm{~cm}^{-1}$ in the complex indicates the coordination of hydroxyl oxygen to metal ion. The shift of $v(C-O-C)$ from $1093 \mathrm{~cm}^{-1}$ in the ligand to $1085.8 \mathrm{~cm}^{-1}$ in the complex, which indicates the coordination of the oxygen in the methoxyl to metal ion. In the spectrum of

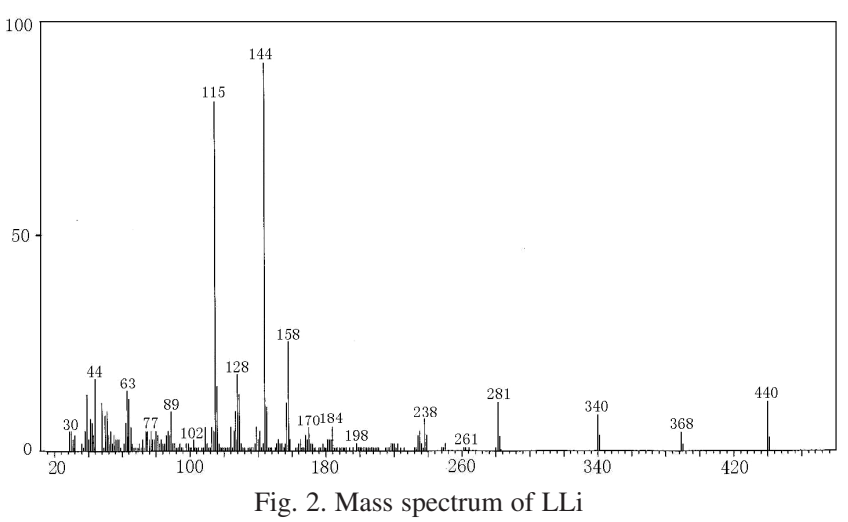

the complex, five additional bands, which are not present in the spectrum of the ligand, were observed. Of these, the bond of $1035 \mathrm{~cm}^{-1}$ is assigned to the $v_{2}$ mode of the nitrate group. The bands of 1489 and $1270 \mathrm{~cm}^{-1}$ in the complex are the two split bands of $v_{4}$ and $v_{1}$, respectively, of the coordinated nitrate group. The magnitude of $v_{4}-v_{1}$ is more than $180 \mathrm{~cm}^{-1}$ for the complex, which indicates that the nitrate group in coordinated to the metal ion in a bidentate fashion. The bands at 1387 and $819 \mathrm{~cm}^{-1}$ are assigned to the non-coordinated nitrate group ${ }^{6}$. The shift of $v_{\text {as }}\left(\mathrm{COO}^{-}\right)$and $v_{\mathrm{s}}\left(\mathrm{COO}^{-}\right)$from 1633 and $1398 \mathrm{~cm}^{-1}$ in the ligand to 1644 and $1398 \mathrm{~cm}^{-1}$ in the complex, respectively, suggests the coordination of the oxygen in the carboxylate group to the metal ion. The magnitude of $\mathrm{v}_{\mathrm{as}}\left(\mathrm{COO}^{-}\right)$$v_{\mathrm{s}}\left(\mathrm{COO}^{-}\right)$is more than $200 \mathrm{~cm}^{-1}$ in the complex, which indicates that the $-\mathrm{COO}^{-}$group is coordinated to the metal ion in a monodentate fashion ${ }^{7}$. The broad bands at $3144 \mathrm{~cm}^{-1}$ in the complex is attributed to $\mathrm{v}(\mathrm{O}-\mathrm{H})$ of phenol and water molecules.

Electronic spectra: The electronic spectrum of the complex in DMSO exhibits two spectral bands at 262 and 382 $\mathrm{nm}$, having the molar extinction coefficients $\varepsilon=2.77 \times 10^{4}$, $7.21 \times 10^{3} \mathrm{~L} \mathrm{~mol}^{-1} \mathrm{~cm}^{-1}$, respectively. These bands occur at $270,375 \mathrm{~nm}\left(\varepsilon=3.65 \times 10^{4}, 9.33 \times 10^{3} \mathrm{~L} \mathrm{~mol}^{-1} \mathrm{~cm}^{-1}\right)$ in the spectrum of the ligand. The change of the molar extinction coefficients suggests that the ligand is coordinated to the metal.

${ }^{1}$ H NMR spectra: The ${ }^{1} \mathrm{H}$ NMR spectra of the ligand and complex $\left[\mathrm{GdL}\left(\mathrm{NO}_{3}\right)\right] \mathrm{NO}_{3} \cdot 2 \mathrm{H}_{2} \mathrm{O}$ were recorded in DMSO- $d_{6}$. In the spectrum of the ligand the phenolic $\mathrm{OH}$ proton appears at $14.21 \mathrm{ppm}$. This signal shifts to $12.68 \mathrm{ppm}$ in the complex spectrum, which indicates that the coordination of phenolic oxygen to metal ions. The peak at $9.37 \mathrm{ppm}$ in the ligand can be assigned to $\mathrm{CH}=\mathrm{N}$ proton. It shifts to $8.74 \mathrm{ppm}$ in the spectrum of the complex, which confirms the coordination of azomethine group to metal ion. In the spectrum of the complex the multisignals within the 7.36-7.58 ppm range were assigned to aromatic $\mathrm{H}$ protons. In the spectrum of the ligand the $-\mathrm{OCH}_{3}$ proton appears at $3.36 \mathrm{ppm}$ and it appears at $3.34 \mathrm{ppm}$ in the complex spectrum, which indicates the $-\mathrm{OCH}_{3}$ is not bound to metal ion.

Thermal decomposition studies: The TG and DTG curves of the complex are shown in Fig. 3, which indicates that the complex decomposes in three steps. The first weight loss stage has a decomposition temperature range of 61-141 ${ }^{\circ} \mathrm{C}$, with a weight loss of $5.12 \%$, which corresponds to the loss of two molecules of water (calcd. $4.80 \%$ ). The fact that the water molecule was lost at a low temperature suggests that 


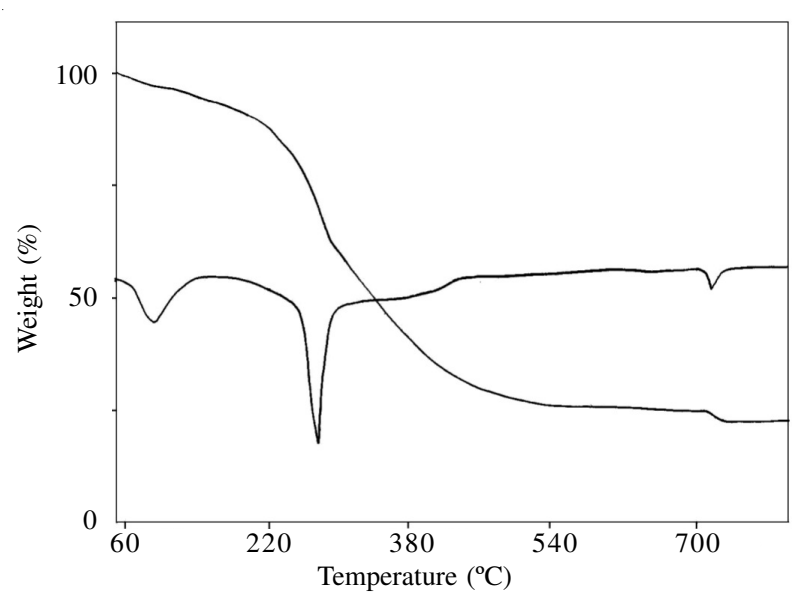

Fig. 3. TG-DTG curves of the complex

the water is crystal water. The second weight loss stage showed a continuous weight loss between 141 and $429^{\circ} \mathrm{C}$, with a weight loss of $58.26 \%$, which corresponds to the loss of unsymmetrical Schiff base ligand (calcd. $57.74 \%$ ). The third stage showed a continuous weight loss between 429 and $770{ }^{\circ} \mathrm{C}$ and $23.88 \%$ of the original sample remained. With its calculated weight percentage of $24.15 \%, \mathrm{Gd}_{2} \mathrm{O}_{3}$ is the final product.

On the basis of 30 kinetic functions in both differential and integral forms commonly used in recent reviews ${ }^{8}$, the nonisothermal kinetics of the steps were investigated using the Achar differential method ${ }^{9}$ and the Coats-Redfern integral method ${ }^{10}$.
The original kinetic data for the second step obtained form the TG and DTG curves are listed in Table-1, in which $T_{i}$ is the temperature at any point $i$ on the TG and DTG curves, $\alpha_{i}$ is the corresponding decomposition rate. $(\mathrm{d} \alpha / \mathrm{dt})_{\mathrm{i}}=\left[\beta /\left(\mathrm{W}_{0}-\mathrm{W}_{1}\right)\right]$ $\times(\mathrm{dW} / \mathrm{dT})_{\mathrm{i}}$ in which $(\mathrm{dW} / \mathrm{dT})_{\mathrm{i}}$ is the height of the peak in the DTG curve, $\beta$ is the heating rate and $\mathrm{W}_{0}$ and $\mathrm{W}_{1}$ are the initial and final weight at that stage, respectively. The calculated kinetic parameters (E, A) and correlation coefficients (r) of steps (2) are listed in Table-2.

\begin{tabular}{|c|c|c|}
\hline \multicolumn{3}{|c|}{$\begin{array}{c}\text { TABLE- } 1 \\
\text { DATA FOR STEP }(2) \text { OF THE } \\
\text { THERMODECOMPOSITION OF }\left[\mathrm{GdL}\left(\mathrm{NO}_{3}\right)\right] \mathrm{NO}_{3} \cdot 2 \mathrm{H}_{2} \mathrm{C} \\
\text { OBTAINED FROM TG AND DTG OF CURVES }\end{array}$} \\
\hline $\mathrm{T}_{\mathrm{i}}(\mathrm{K})$ & $\alpha_{i}$ & $(\mathrm{~d} \alpha / \mathrm{dt})_{\mathrm{i}}$ \\
\hline 543 & 0.2342 & 0.0918 \\
\hline 547 & 0.3092 & 0.1210 \\
\hline 549 & 0.3223 & 0.1354 \\
\hline 550 & 0.3861 & 0.1422 \\
\hline 551 & 0.4064 & 0.1497 \\
\hline 552 & 0.4882 & 0.1585 \\
\hline 553 & 0.4950 & 0.1667 \\
\hline 554 & 0.5258 & 0.1592 \\
\hline 555 & 0.5479 & 0.1510 \\
\hline 556 & 0.5660 & 0.1449 \\
\hline 557 & 0.5787 & 0.1347 \\
\hline 559 & 0.6293 & 0.1204 \\
\hline 563 & 0.7288 & 0.0912 \\
\hline
\end{tabular}

TABLE-2

RESULTS OF ANALYSIS OF THE DATA FOR STEP (2) IN TABLE-1 BY ACHAR DIFFERENTIAL METHOD AND COATS-REDFERN INTEGRAL METHOD

\begin{tabular}{|c|c|c|c|c|c|c|}
\hline No. & $\mathrm{E}(\mathrm{kJ} / \mathrm{mol})$ & $\ln \left(\mathrm{A} / \mathrm{s}^{-1}\right)$ & $\mathrm{r}$ & $\mathrm{E}(\mathrm{kJ} / \mathrm{mol})$ & $\ln \left(\mathrm{A} / \mathrm{s}^{-1}\right)$ & $\mathrm{r}$ \\
\hline 1 & 153.5 & 31.08 & 0.7747 & 294.3 & 49.81 & 0.9717 \\
\hline 2 & 211.9 & 43.63 & 0.8695 & 328.8 & 56.82 & 0.9763 \\
\hline 3 & 235.4 & 47.34 & 0.8937 & 342.4 & 58.35 & 0.9779 \\
\hline 4 & 280.4 & 54.36 & 0.9257 & 369.8 & 64.47 & 0.9806 \\
\hline 5 & 105.5 & 18.26 & 0.66 & 261.18 & 40.15 & 0.9689 \\
\hline 6 & 415.5 & 87.43 & 0.9679 & 459.9 & 84.52 & 0.9862 \\
\hline 7 & 135.9 & 28.24 & 0.8647 & 201.9 & 30.83 & 0.9831 \\
\hline 8 & 65.54 & 12.68 & 0.6851 & 131.6 & 15.68 & 0.9823 \\
\hline 9 & 30.36 & 4.82 & 0.4207 & 96.37 & 8.10 & 0.9814 \\
\hline 10 & -4.83 & -3.17 & 0.0782 & 61.18 & 0.520 & 0.9796 \\
\hline 11 & -22.42 & -7.24 & 0.3511 & 43.59 & -3.27 & 0.9774 \\
\hline 12 & 68.37 & 12.51 & 0.6234 & 170.2 & 23.07 & 0.9776 \\
\hline 13 & 90.88 & 17.12 & 0.7372 & 180.3 & 24.92 & 0.9797 \\
\hline 14 & 0.820 & -1.83 & 0.0087 & 142.5 & 17.59 & 0.9699 \\
\hline 15 & -75.04 & -18.64 & 0.6819 & 66.67 & 1.48 & 0.9657 \\
\hline 17 & -113.0 & -27.39 & 0.8352 & 28.74 & -6.58 & 0.9545 \\
\hline 18 & 270.0 & 58.30 & 0.9879 & 275.6 & 49.69 & 0.9886 \\
\hline 19 & 203.5 & 42.58 & 0.9396 & 58.35 & 0.410 & 0.9737 \\
\hline 20 & -49.75 & -12.98 & 0.5058 & 91.96 & 6.85 & 0.9679 \\
\hline 21 & 347.0 & 74.39 & 0.9527 & 413.0 & 76.29 & 0.9838 \\
\hline 22 & 558.2 & 120.26 & 0.9677 & 624.2 & 121.75 & 0.984 \\
\hline 23 & 769.3 & 166.01 & 0.9734 & 835.3 & 167.21 & 0.9842 \\
\hline 24 & 406.1 & 89.08 & 0.9837 & 261 & 45.51 & 0.9787 \\
\hline 25 & 102.1 & 19.33 & 0.7792 & 185.6 & 25.8 & 0.9806 \\
\hline 26 & -134.3 & -31.21 & 0.7627 & 98.34 & 8.39 & 0.9475 \\
\hline 27 & -269.4 & -60.88 & 0.8923 & 66.67 & 1.67 & 0.9158 \\
\hline 28 & -404.5 & -90.66 & 0.9297 & 44.42 & -3.09 & 0.8745 \\
\hline 29 & -3.87 & -3.35 & 0.0555 & 85.57 & 5.15 & 0.9774 \\
\hline 30 & 30.44 & 3.76 & 0.3626 & 80.51 & 4.22 & 0.9750 \\
\hline
\end{tabular}


The results obtained from the two different methods are approximately the same when based on function No. 18. The kinetic equation is expressed as: $\mathrm{d} \alpha / \mathrm{dt}=\mathrm{A} \mathrm{e}^{-\mathrm{E} / \mathrm{RT}}(1-\alpha)^{2}, \mathrm{E}=$ $272.8 \mathrm{~kJ} / \mathrm{mol}, \ln \mathrm{A}=54.00, \mathrm{r}=0.9883$.

The activation entropy $\Delta \mathrm{S}^{\neq}$and activation free-energy $\Delta \mathrm{G}^{\neq}$ are calculated by the following equations ${ }^{11}: \mathrm{A}=\mathrm{kT}_{\mathrm{s}} \exp \left(\Delta \mathrm{S}^{\mp} /\right.$ $\mathrm{R}) / \mathrm{h}, \mathrm{A}^{\mathrm{e}-\mathrm{E} / \mathrm{RT}}=\mathrm{kT}_{\mathrm{s}} \exp \left(\Delta \mathrm{S}^{\neq} / \mathrm{R}\right) \exp \left(-\Delta \mathrm{H}^{\neq} / \mathrm{RT}\right) / \mathrm{h}, \Delta \mathrm{G}^{\neq}=\Delta \mathrm{H}^{\neq}-$ $\mathrm{T} \Delta \mathrm{S}^{\neq}$, in which $\mathrm{T}_{\mathrm{s}}$ is the temperature at the top of peak (2), $\mathrm{k}$ is Boltzmann constant, $\mathrm{R}$ is gas constant, $\mathrm{h}$ is Plank constant. The activation entropy $\Delta \mathrm{S}^{\neq}$and activation free-energy $\Delta \mathrm{G}^{\neq}$for second thermal decomposition stage were gained, $\Delta \mathrm{S}^{\neq}=198.9$ $\mathrm{J} / \mathrm{mol} \mathrm{K}, \Delta \mathrm{G}^{\neq}=162.8 \mathrm{~kJ} / \mathrm{mol}$.

\section{Conclusion}

The results presented here indicate that L-lysine can react with $o$-vanillin and 2-hydroxy-1-naphthaldehyde forming unsymmetrical Schiff base LLi and gadolinium nitrate can form stable solid complex with this ligand. The composition of the complex is confirmed to be $\left[\mathrm{GdL}\left(\mathrm{NO}_{3}\right)\right] \mathrm{NO}_{3} \cdot 2 \mathrm{H}_{2} \mathrm{O}$. The kinetic equation for second decomposition step may be expressed as: $\mathrm{d} \alpha / \mathrm{dt}=\mathrm{A} \mathrm{e}^{-\mathrm{E} / \mathrm{RT}}(1-\alpha)^{2}, \mathrm{E}=272.8 \mathrm{~kJ} / \mathrm{mol}, \ln \mathrm{A}=54.00, \mathrm{r}=$ $0.9883, \Delta \mathrm{S}^{\neq}=198.9 \mathrm{~J} / \mathrm{mol} \mathrm{K}, \Delta \mathrm{G}^{\neq}=162.8 \mathrm{~kJ} / \mathrm{mol}$.

\section{ACKNOWLEDGEMENTS}

This work was supported by the National Science Foundation of China (No. 20971115 and No. 21071134).

\section{REFERENCES}

1. Q. Wang, C.F. Bi, Y.H. Fan, X. Zhang, J. Zuo and S.B. Liu, Russ. J. Coord. Chem., 37, 228 (2011).

2. X. Zhang, C.F. Bi, Y.H. Fan, Q.Z. Cui, D. Chen, Y. Xiao and Q.P. Dou, Int. J. Mol. Med., 22, 677 (2008).

3. Y. Xiao, C.F. Bi, Y.H. Fan, C. Cui, X. Zhang and Q.P. Dou, Int. J. Oncol., 33, 1073 (2008).

4. Y.H. Fan, S.Y. Bi, Y.Y. Li, C.F. Bi and S.T. Xie, Russ. J. Coord. Chem., 34, 772 (2008).

5. W.J. Geary, Coord. Chem. Rev., 7, 81 (1971).

6. N.F. Curtis and Y.M. Curtis, Inorg. Chem., 4, 804 (1965).

7. Q.L. Xu, L.J. Sun, H. Li, R.J. Wu and H.G. Wang, Appl. Organomet. Chem., 8, 57 (1994).

8. Y.Z. Li, Thermal Analysis, Qinghua University Press, Beijing, p. 94 (1987).

9. B.N. Achar, Proceeding International Clay Conference, Jerusalem, Book 1, p. 67 (1966).

10. A.W. Coats and J.P. Redfern, Nature, 201, 68 (1964).

11. R.Z. Hu and Q.Z. Shi, Thermal Analysis Kinetics, Science Press, Beijing, p. 206 (2001). 